Virtual Mentor. November 2004, Volume 6, Number 11.

doi: 10.1001/virtualmentor.2004.6.11.pfor1-0411

Policy Forum

\title{
The Need for a Centralized Clinical Trials Registry
}

\section{A centralized registry to provide information to consumers regarding the effectiveness of clinical trials is needed to help patients make informed decisions about treatment.}

\author{
Christian J. Krautkramer and Shane K. Green, PhD
}

Imagine waking up one morning to headlines touting the discovery of a remarkable new drug, Somax. The acclaim is based on a clinical trial with thousands of participants, the unprecedented results of which have just been published in one of the world's top medical journals. Soon, television ads will offer the promise of improved health and well-being, with a reassuring voice encouraging you to seize the opportunity: "ask your doctor if Somax is right for you!" And why not? The study has been vetted by experts and the data and conclusions have been judged sound; Somax may be just the thing to treat your ailment.

Is this scenario too good to be true? It's hard to say, especially if you are not given the whole story. Yet under current clinical reporting guidelines, the manufacturers of Somax have no obligation to disclose "proprietary information," which may include data from other trials, even if those data suggested that Somax was less effective than other medications, altogether ineffective, or even potentially harmful to those taking it.

Global sales of pharmaceuticals amount to approximately $\$ 350$ billion annually, so the makers of Somax have powerful economic incentives to withhold all but the most positive of findings; after all, there would be scarce marketshare for a drug shown to have questionable efficacy or benefits that are outweighed by associated risks. Granted, the pharmaceutical industry is a business and is, therefore, entitled to earn a profit; these profits, in turn, help fund further biomedical research and innovation. There must be a point, however, at which that entitlement is superseded by the interests of the patient-consumer-caveat emptor should not apply to inherently vulnerable patients.

Though the above scenario is hypothetical, the underlying issue unfortunately is not. Concerns over the nondisclosure of negative or inconclusive clinical trial data came to a head this past August when an FDA review, prompted by a tragic incident, confirmed that pharmaceutical manufacturers had withheld study results that suggested an increase in suicidal ideation among children taking certain antidepressant medications (specifically, Paxil from GlaxoSmithKline (GSK), and Pfizer's Zoloft) [1].

The practice of nondisclosure, by no means limited to these recent high-profile cases, is finally garnering the attention it deserves, and long overdue steps are being taken to counter it.

\section{Why disclose all clinical trial data?}

Once a drug is approved by the FDA and reaches the marketplace, it is critical that all information on that drug's past performances be available to physicians and patients alike, for one simple reason: physicians cannot practice evidencebased medicine, nor can patients expect to benefit from evidence-based medical advice, if key evidence is suppressed. Indeed, it is the potential for the suppression of evidence (ie, negative clinical trial data) to cause harm to patients, albeit indirectly, that has brought this issue to the fore. 
Disclosure is also important for those individuals who participate in the clinical testing (ie, pre-approval) of new drugs. When people consent to be subjects in clinical trials, they do so in spite of the distinct possibility that the experimental intervention may offer them no benefit, and, in fact, may cause them harm. Why? Healthy volunteers may be motivated to participate in Phase I trials by the promise of financial remuneration. Patients with seemingly incurable disease may enroll in Phase III trials in hopes that the experimental therapy available to trial subjects will succeed where conventional treatments failed. But many, if not most, participate in clinical trials with the altruistic intention of contributing to medical knowledge that may help improve human health and well-being [3].

By asking prospective subjects to assume the risk inherent to clinical testing so that others may benefit from the findings, researchers take on implicit responsibility to minimize that risk and ensure that the remaining, unavoidable risk is not taken in vain. Full disclosure of previous clinical trial data (ie, data from any and all prior trials of a given drug) is essential to meet these responsibilities, for several reasons.

First, the data from each phase of pre-market clinical trial testing (ie, Phase I, II and III) provides the foundation for the next phase of tests, or for more testing at the same level, in part by helping to mitigate risk to subjects in subsequent tests. If clinical trial data is suppressed, it cannot inform the design or conduct of subsequent trials and, therefore, cannot be used as it ought to be: to protect subjects from possible harm.

Second, before clinical research can be undertaken, trial proposals are vetted by Institutional Review Boards (IRBs), which are charged with ensuring that the risk of harm to participants is not undue, unnecessary, or unmitigated. But IRBs are precluded from performing their function effectively if they are not privy to all available information concerning the experimental treatment, including data on past trial performance.

Finally, the potential for others to benefit from a trial subject's assumption of any unavoidable risk becomes moot if the data generated in the course of study are buried [4]. This is particularly objectionable in cases where actual harm is incurred by research subjects, whose sacrifices are worthwhile only if they are disclosed, thereby mitigating potential future harms to others [5].

\section{Recommendations of the ICMJE}

The International Committee of Medical Journal Editors (ICMJE), which comprises the editors of 11 of the world's top medical journals, has recently taken a significant step to combat the problem of "selective awareness" of clinical trials. In an editorial published simultaneously in all member journals [6], the ICMJE announced a new policy to the effect that, beginning next year, papers describing clinical trial results would only be considered for publication in member journals if the trial had been registered, prior to volunteer enrollment, in an open registry that met certain criteria.

Acceptable registries will be those that include a unique trial identification number, a statement of the intervention(s) and comparison(s) studied, the study hypothesis, primary and secondary outcome measures, participant eligibility criteria, key trial dates, target number of subjects, funding source(s), and contact information for the principal investigator(s). Moreover, the registry must be open to the public at no cost, be electronically searchable, and be maintained by a not-for-profit group (ie, registries operated by GSK or Eli Lilly \& Co., for example, do not qualify). According to the editors, the only current registry that meets the criteria is www.clinicaltrials.gov, maintained by the National Institutes of Health.

This important policy, however, applies only to ICMJE member journals, and, while they are among the most respected medical journals in the world, there are hundreds of others that publish clinical trial results; hence, the ICMJE has recommended that all journals adopt similar policies concerning trial registration.

Though they represent a laudible initial step toward the ultimate goal of openness in clinical research, the recommendations of the ICMJE fall short of what is needed, for 2 main reasons: First, they do not mandate that the results of trials be entered in a registry, meaning that negative data could (and likely would) remain undisclosed; and second, the ICMJE does not advocate for a single, centralized registry, the lack of which will make it significantly more difficult for patients, physicians, and researchers to acquire and make use of all pertinent information on trials of a given drug or class of drugs. 


\section{Negative Results}

For physicians to make informed clinical decisions as to the best treatment options available to their patients, they must be able to weigh possible harms against likely benefits [7]. Not surprisingly, information concerning potential benefits is easy for physicians to come by; journal articles, continuing medical education activities, and pharmaceutical company representatives provide a very detailed picture about which drugs constitute the cutting edge therapy for a particular ailment. In contrast, negative results (eg, those indicative or suggestive of serious side effects) sometimes remain unreported [8]. Merely registering clinical trials before they are conducted will not rectify this imbalance.

To succeed in addressing the issue of selective awareness, a registry must include descriptions of trials' outcomes, be they positive, negative, or inconclusive. This is not, however, as simple as it sounds; studies are often closed or not submitted for publication based on questionable experimental methodology, therefore trial results must not only be released but also explained in good faith or, at minimum, qualified. The inclusion of outcome reporting in a clinical trials registry would do little to change the frequency of publication of negative data in peer-reviewed journals, but it would bring the data into the public domain where it can be accessed by patients and physicians alike.

\section{Centralized Registry}

Multiple clinical trial registries, even if each meets all the criteria set forth by ICMJE, would necessitate that physicians, researchers, and patients locate and investigate many sources to acquire a full complement of available information. In addition to being unnecessarily inefficient, such an approach increases the risk that important information will be missed. A single, authoritative source of information on established and experimental therapies would drastically reduce that risk, and allow for far more efficient and effective data collection.

Hence, we support creation of a comprehensive registry, to include all trials conducted in the US and all international trials sponsored by US-based groups, housed in the National Institutes of Health (NIH), and accessible through the National Library of Medicine (NLM). The heart of the US clinical-research establishment, the NIH is already home to www.clinicaltrials.gov, which could, at least in theory, be modified to become a more comprehensive trial registry. Moreover, NLM is host to several searchable databases of medical literature, notably including MEDLINE, the world's most comprehensive, and most searched, medical journal database. Putting the trial registry in proximity (in a virtual sense) to the NLM databases would greatly facilitate one's ability to access all available data, published and unpublished.

There is currently a bill pending before the US Senate, S.2933 [9], and supported by the American Medical Association [10], that similarly recommends the creation of a clinical trials registry to be housed at the NIH. The registry would contain information on all publicly and privately funded clinical trials involving drugs, biological products, or devices, from start to finish, regardless of the outcome of the trial. Furthermore, registration of trials would be mandatory, with strict penalties for non-compliance. Support for this bill from the clinical research community and its benefactors - health care consumers-would add momentum and increase pressure to pass this important legislation.

\section{Conclusion}

To best serve their patients, physicians must be as informed as possible. To be truly empowered and provide genuine consent to treatment, patients must be as informed as possible. To reduce redundancy in experimentation, at great cost and potentially great risk to human subjects, clinical researchers must be as informed as possible. For all of these parties, a centralized, comprehensive clinical trial registry would redefine, to their benefit, what it means to be "as informed as possible"—what more justification could one require?

Conceivably, some individual or collective actors will, in the interest of prioritizing profits, continue to devote great effort to protecting trade secrets or burying bad results that could prevent a financial windfall. Therefore, pressure must be placed on the pharmaceutical industry, FDA, researchers, journal editors, and legislators to institute a singular, comprehensive, and mandatory registry for all clinical trials, as an essential means by which to ensure that new drugs 
help patients as well as pocketbooks.

\section{References}

1. Lamb, GM. Veil of secrecy to lift on drug tests. Christian Science Monitor. September 13, $2004 ;$ Features:11.

2. Kolata G. A Widely Used Arthritis Drug Is Withdrawn. New York Times. October 1, 2004;sect A:1. Google Scholar

3. Dowd MD. Breaching the contract: the ethics of nonpublication of research studies. Arch. Pediatr. Adolec. Med. 2004;158:1014-15. View Article PubMed Google Scholar

4. Dickersin K, Rennie D. Registering clinical trials. JAMA. 2003;290:516-523. View Article PubMed Google Scholar

5. Federman DD, Hanna KE, Rodriguez LL, ed. Responsible Research: A Systems Approach to Protecting Research Participants. Committee on Assessing the System for Protecting Human Research Participants. Institute of Medicine. Washington, DC: The National Academies Press;2002. Google Scholar

6. DeAngelis CD, Drazen JM, Frizelle FA, et al. Clinical trial registration: a statement from the International Committee of Medical Journal Editors. JAMA. 2004;292:1363-1364. Google Scholar

7. Rennie D. Trial registration: a great idea switches from ignored to irresistible. JAMA. 2004;292:1359-1362. View Article PubMed Google Scholar

8. Steinbrook R. Public registration of clinical trials. N Engl J Med. 2004;351:315-317. View Article PubMed Google Scholar

9. US Senate. S.2933: Fair Access to Clinical Trials Act of 2004. Washington, DC:108th Congress. 2004.

10. AMA provides outline for developing national clinical trials registry [press release]. Chicago: American Medical Association; September 9, 2004.

The viewpoints expressed on this site are those of the authors and do not necessarily reflect the views and policies of the AMA.

(C) 2004 American Medical Association. All Rights Reserved. 